\title{
The Organization of Studying and Research Activities of Students by the Methods of Pedagogical Intellectics
}

\author{
V. Punchyk ${ }^{1}$ \\ ${ }^{1}$ Belarusian State Pedagogical University named after Maxim Tank.
}

\begin{tabular}{l} 
ARTICLE INFO \\
\hline Keywords: \\
cognitive; \\
comprehension; \\
concepts; design; \\
intellectics; learning; \\
representative structures; \\
semantic network; \\
students' activity.
\end{tabular}

\begin{abstract}
The expediency of the organization of students' studying and research activities from the perspective of a cognitive approach by methods of pedagogical intellectics is grounded. The logic of learning component-wise design is described (using didactic examples), the prototype of which is solving the problem of extracting expert knowledge. The content and features of the implementation of the author's technique of rational organizing students' studying and research activities on the basis of didactic concepts' design are revealed. It is confirmed that the pedagogical intellectics is a solution of transferring the pedagogical potential of the individual from the existence to the development.
\end{abstract}

\section{Introduction}

One of the education development priorities is the improvement of content and organization of its process. In the context of resolving the key contradiction of the modern education system - between the rapid growth of knowledge and the limited capability of person comprehension - the future specialists training is complemented by the innovation component, which consists in shaping students' needs and opportunities to go beyond the limits of the subject. On the one hand, this is due to the acquirement of topical basic knowledge of the subject area, and on the other hand, with the development of our own cognitive mobility, taking into account the individual characteristics of the knowing subject personality.

One of the main components of the subject area knowledge system and specific research are concepts. The concepts provide the subject of cognition the free operation with abstract concepts in conditions of uncertainty, and also forms the basis for making objective decisions and forecasting, since thinking always moves in the pyramid of concepts (Vygotsky, 1956). Sources of concept formation are both expert knowledge and subjective experience.

A receptive-reflective position in the organization of this process is typical for the majority of previous researches, which is associated with the use of a predominantly explanatory-illustrative and receptive teaching methods. The possibilities of independent cognitive activity of students

\footnotetext{
$\square$ Corresponding Author E-Mail Address: zelda@tut.by
} 
from the position of a cognitive approach in improving the quality of concepts comprehension have not been studied enough.

In previous researches the quality of comprehension of concepts was considered mainly in the result aspect which characterizes the final side of this process. The procedural aspect of quality which indicates the student's actions in mastering concepts, and its substantive aspect, which reflects the disclosure by students of the concepts content in the process of their mastery and representation was not given due attention.

The problem of mastering the concepts of students is also relevant to the context of general educational training. The content-analysis of 40 textbooks and teaching manuals on pedagogy and an ascertaining experiment to assess of didactic concepts comprehension by students has shown that concepts are not always considered as an integral system, relationships between concepts are established speculatively, which leads to insufficient quality of their comprehension by students (Tsyrkun, Punchyk, 2011). For example correctly formulated the definitions of the main didactic concepts $25.8 \%$ of respondents; some connections between the concepts indicated $4.6 \%$; the narration of the concept was not systemic in $78.8 \%$ of respondents.

A wide-context sight to the problem of organizing educational and research activities of students in the logic of a cognitive approach involving transdisciplinary knowledge suggests an appeal to relevant integrative areas of scientific knowledge, one of which is pedagogical intellectics. Pedagogical intellectics is a knowledge system about various aspects of human activity in solving cognition tasks using various methods and means of intellectual activity (Tsyrkun, Punchyk, 2011). It is in the field of competing solutions to the problem of transferring the pedagogical potential of an individual from a state of hidden existence to development.

Hypothesis: the application of pedagogical intellectics methods allows the complex and effective solution of the problem of organizing the educational and research activities of students, which indicator is the quality of concepts' comprehension by the students.

The results of the research are invariants for the whole comprehension process, and in this article they are considered on the example of the comprehension of didactic concepts.

\section{Body}

\subsection{The Conceptual Bases of Studying and Research Activities Organization of Students by the Methods of Pedagogical Intellectics}

A requirements for modern specialist are includes a high level of analytical thinking, possession of intellectual skills and abilities, the ability to independently master new knowledge, which is impossible without deep mastering of leading ideas, concepts, laws and other elements of the knowledge system. One of its main components are concepts, the comprehension of which plays an extremely important role in the development of students' ability to theoretical thinking, interest in the theoretical component of professional activity. In the pedagogical process, concepts act as a form of thinking, a means of cognition new things and its results.

Consideration of the problem of concepts comprehension from the standpoint of the cognitive approach allows us to understand the logic of the ongoing cognitive processes. In the context of the psychosemantic paradigm, the psychophysiological basis of the process of concept formation is representative cognitive structures that serve as the basic means of cognition of reality. The content of the concept the "representative cognitive structures" can be revealed in the following provisions (Chuprikova, 2003, p. 11): 1) cognitive structures are a way of recording information 
in long-term memory - this way of recording reflects stable invariant characteristics and relations of the objective world and its components, internal states of the subject and subject-subject relations; 2) cognitive structures form systems consisting of sub-systems and hierarchical levels - such systems are the main tools of cognition; 3) in the aggregate, cognitive structures are the schemes through which a person analyzes and synthesizes all the incoming information.

The position on the internal substrate of mental development which differs from the externally observable mastering of knowledge was first formulated in Russian science by L. S. Vygotsky. L. M. Vekker substantiated the position for a clear level-by-level structures organization of conceptual thinking (Vekker, 1998). The carriers of mental processes are complex cognitive structures, which at all levels of the organization include space-time components and have a different number of hierarchical levels. As proved in a number of psychological researches, it is not individual components of perceptions that are recorded in a person's memory, but a certain result of their mental integration. According to computer metaphor of cognition (Lobanov, Zhuravkina, 2018) there are several types of memory, the mastered concepts are stored in the socalled "semantic memory". It allows you to use language, to realize abstract thinking and represents some "mental thesaurus" (Chuprikova, pp. 169-170), which organizes human knowledge.

Mental reflections of objects and phenomena are subjected to cognitive processing which the result is a generalized schematic representation of these objects and phenomena. It should be separated from its specific properties. According to the symbolic note, they also indicate that concepts exist not separately in consciousness, but are connected in some way, forming a cognitive structure in the form of a semantic field, which can be materialized as an intellect- (semantic) map.

According to experimental researches on the human experience study based on a comparison of cognitive structures of experts and beginners in a certain field of activity (Chervinskaya, 2003), the difference between the cognitive structures of experts is insignificant, but significant compared with all kinds of beginners' cognitive structures. In this context, the extracted expert knowledge objectively reflects the current state of the research problem or subject area. Therefore the cognitive structure which is a way of representing concepts in the mind of an expert and reflecting the essence of knowledge of the subject area, should be considered as a generalized direction of studying.

It actualizes the classical problem of transfer, which can be solved in the context of the knowledge-modeling paradigm by building models that reflect the understanding of the experts' subject matter in general. The construction of the subject area concepts system is the dominant complex method of pedagogical intellectics. This method assumes the consequential conversion from the stages of knowledge extraction to their conceptual synthesis. The contents of these stages are presented in Table 1. 
Table 1. Stages of designing the subject area concepts system

\begin{tabular}{|l|l|l|}
\hline Stages methods & \multicolumn{1}{|c|}{ Stage content } & \multicolumn{1}{|c|}{ Providing methods } \\
\hline $\begin{array}{l}\text { 1. Knowledge } \\
\text { extraction }\end{array}$ & $\begin{array}{l}\text { 1.1 Determination the consistency } \\
\text { of the concepts system }\end{array}$ & $\begin{array}{l}\text { Content-analysis of knowledge sources } \\
(1.1 .1) \text {; frequency analysis (1.1.2) }\end{array}$ \\
\cline { 2 - 3 } $\begin{array}{l}1.2 \text { Definition of the main } \\
\text { concepts content }\end{array}$ & $\begin{array}{l}\text { Structural analysis of definitions } \\
(1.2 .1) \text {; method of "virtual" expertise } \\
(1.2 .2)\end{array}$ \\
\hline $\begin{array}{l}2 . \quad \text { Conceptual } \\
\text { synthesis }\end{array}$ & $\begin{array}{l}2.1 \text { Structuring the concepts } \\
\text { system }\end{array}$ & $\begin{array}{l}\text { Designing a semantic network (2.1.1); } \\
\text { ranking of concepts (2.1.2) }\end{array}$ \\
\hline
\end{tabular}

To determine the consistency of the concept system (1.1) it is advisable to use the method of content-analysis of various sources of expert knowledge: monographs, articles, theses, other written works, lecture materials, speeches, reports, interviews, etc. The composition of the concept system bases on the frequency analysis with the value of the frequency coefficient of each concept.

To determine the main content of the selected concepts (1.2) a structural analysis of their definitions is carried out the essence of which is to determine the nearest generic concept and highlight its distinctive essential attribute.

The next step in the modeling of expert knowledge is a conceptual analysis (2), which results in the presentation of the identified concepts in the form of a specific semantic representation (cognitive structure). The type of cognitive structure is determined by the types of basic semantic relations. Relationships of concepts are established by comparing the relations between their essential attribute. There is a finite number of basic relationships in the reality, the rest of the variety is a combination of basic (Pospelov, 1977). The following types of relationships can be found between the concepts: classifications (which allow classifying concepts: "species - genus", "part - whole", "to be a part"); attributive (attributing qualitative signs to concepts: "to have an attribute", "to have a value of an attribute"); comparisons (comparing two characteristics of a concept or several concepts among themselves according to a characteristic or quantitative relation: "comparison"); implementation (connecting concepts on the basis belong to a particular situation: "to belong"); timing (defining the dynamic characteristics of the element: "to be earlier"); causal (reflecting causal relationships: "to be a goal", "to have a goal"); instrumental (connecting the pragmatic aspect of activity: "to be an instrument", "to be an auxiliary tool", "to serve for"); informational (describing various aspects of transmitting and receiving information: "to be a recipient"), etc.

The semantic field has the form of a semantic network when the result of the conceptual analysis revealed several types of relationships between concepts and their attributes. Such cognitive structure can be represented as a directed graph which vertices are the concepts and their attributes and the arcs characterize the relations between them.

The semantic network of specific subject concepts a domain is advisable to consider as a generalized guideline of comprehension. The semantic network is not a direct object of comprehension, but it's an object of self-design. This decision is one of the mechanisms for implementing the classical transfer problem. As pointed out by J. Bruner (Bruner, 1977), its solution allows to organize the mastery of knowledge according to the peculiarities of thinking. 
Consideration of the quality of concepts' comprehension by the students in the unity of procedural, substantive and result aspects actualized the development of a metasemantic (or metasemantic) concept's notion (term by V. Punchyk), which include meta-knowledge concept's notion, semantic network of concepts system and concepts' structural-logical model (Fig. 1).

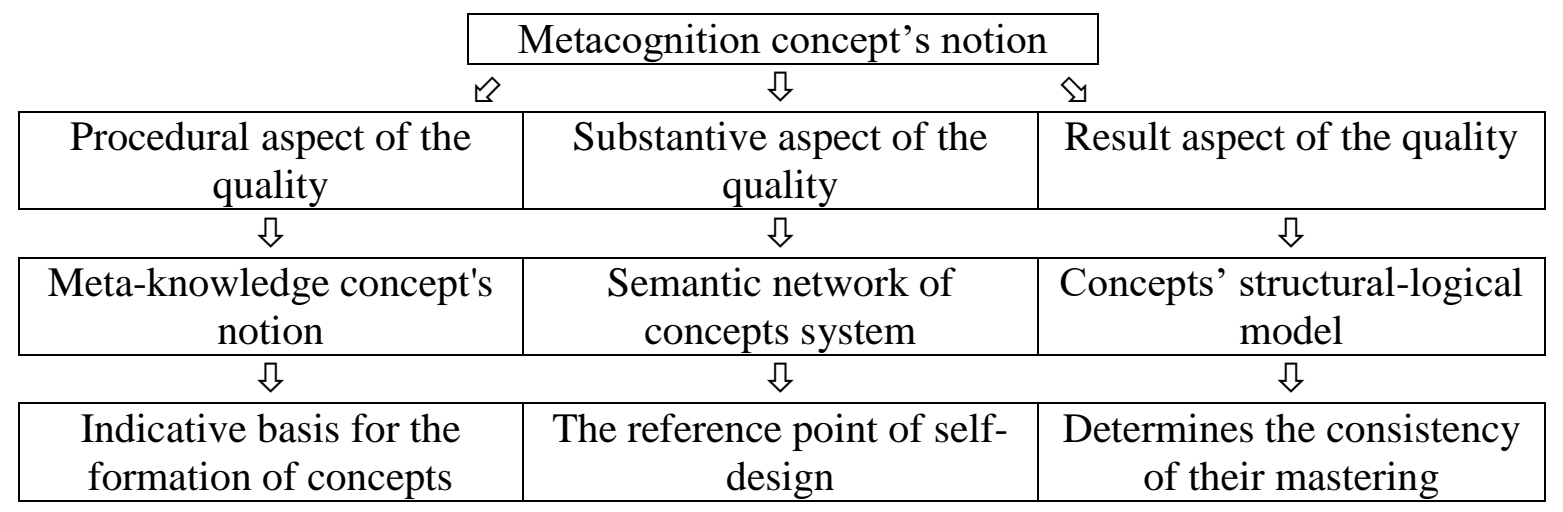

Fig. 1. The structure and description of metacognition concept's notion

The meta-knowledge concept's notion realizes the procedural aspect of concepts' quality comprehension by the students. It acts an indicative basis for the formation of students' concepts. Meta-knowledge concept's notion has the following structure:

1.the genesis of the concept,

2. the main content of the concept,

3. the scope of the concept,

4. the place in the system of the subject area concepts,

5. the application area,

6. ways of operationalization,

7. limits of applicability.

The semantic network of concepts system realizes the procedural aspect of concepts' quality comprehension by the students. Fig. 2 is presented the fragment semantic network of didactic concepts. It is a cognitive structure of didactic concepts' representation according the work of "virtual" experts - I. Ya. Lerner and V. V. Kraevsky. It contains the main didactic concepts "learning method" and clusters of its attributes.

The semantic network of didactic concepts' system of each student is a material result of their self-design and comprehension. It will be different between each student and be different from the expert version.

The structural-logical model of didactic concepts determines the consistency of their mastering. It includes the concepts which distributed by rank with connection to the central didactic concept "the learning":

- concepts of the 1st rank: education, upbringing, comprehension, the pedagogical process, pedagogical activity, the pedagogical system;

- concepts of the 2nd rank: the purpose of learning, the learning process, teaching, studying;

- concepts of the 3rd rank: the content of learning, the regularity of learning, the principle of learning, the rule of learning;

- concepts of the 4th rank: the learning method, the learning tool, the form of learning, the diagnostics of learning. 


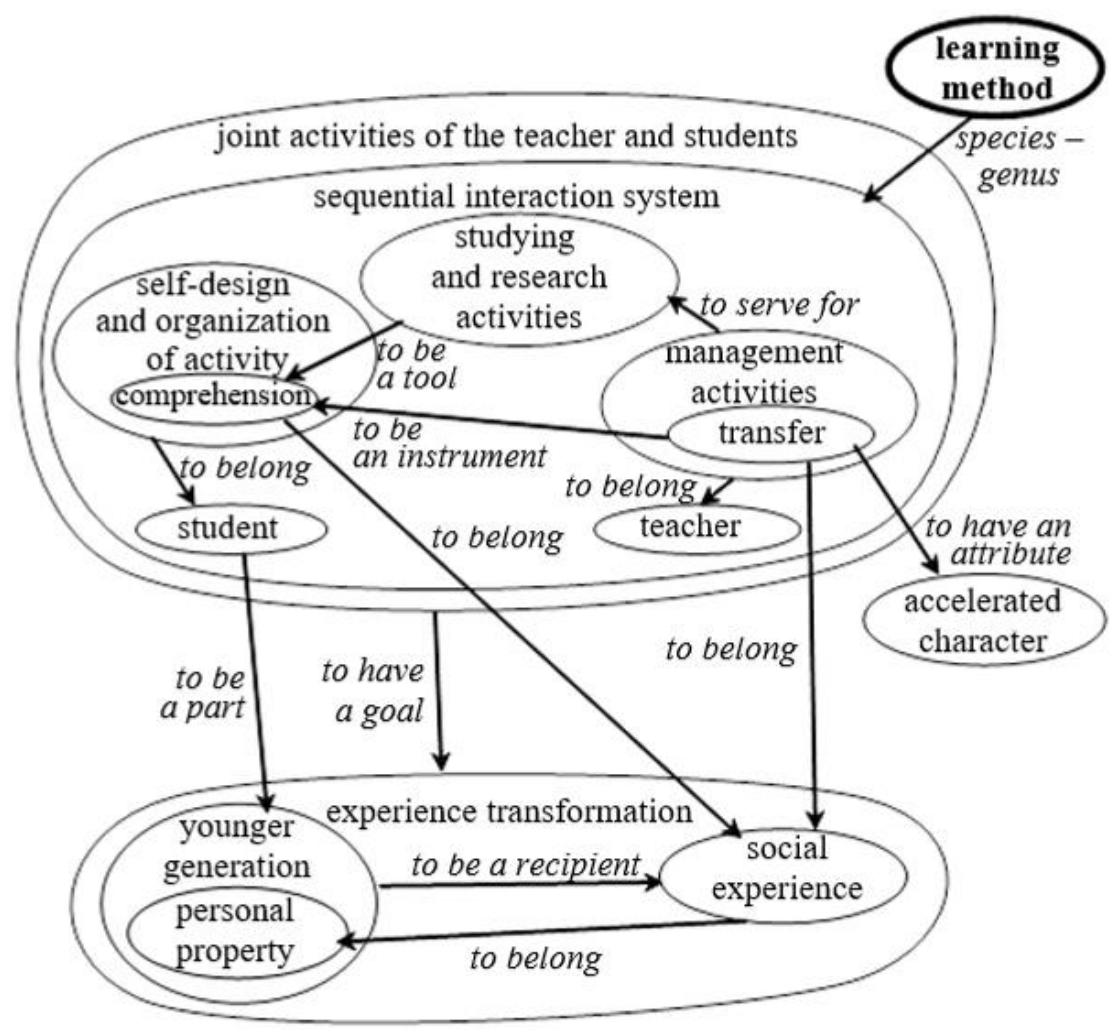

Fig. 2. Semantic network of didactic concepts (fragment)

Consideration of metacognition about the concept as a generalized guideline of comprehension allowed us to identify the following quality criteria: the degree of mastery of meta-knowledge concept's notion, the component-wise comprehension completeness of the concepts' content and the way of representing the system of concepts in the student's consciousness.

\subsection{The technique of rational organizing students' studying and research activities on the basis of didactic concepts' design}

Based on activity theory of learning that the basis and condition for the formation of concepts are objective actions, consideration the andragogic principle of the priority of independence in learning, the transition from a receptive-reflective position to a constructive activity, and the need for equipping students the mechanism of conscious and generalized self-mastering of concepts were actualized us to define special kind of student studying and research activities. We defined it as activity of component-wise design of concepts. According to the content of metacognition concept's notion as a generalized guideline of comprehension this kind or activity includes: fixing the concept; actualizing the pre-scientific concept of the concept; disclosure of the genesis of the concept; definition of the concept's main content; the establishment of the concept's scope; clarification of attributes of the concept; inclusion of the concept in the semantic network; clarification of concepts' attributes in the semantic network; enrichment of the semantic network; finding the application area; definition of ways to operationalize the concept; establishing the limits of applicability of the concept; clarification of its content. 
These conceptual foundations was the base to develop the author's technique of rational organization of students' studying and research activities on comprehension concepts, which implements the logic of their component-wise design. Its essence reveals on the content of the mastering of didactic concepts. This technique includes 2 propaedeutic stages and main stage.

The 1st propaedeutic stage of the formation of didactic concepts was carried out in the process of learning the discipline "General Foundations of the Pedagogical Profession" and the section "Methodological Foundations of Pedagogics" of the course " Pedagogics of the Modern School". There were special tasks included in the learning process for the development of students' mental operations, they were aimed at the awareness of students of analytical and synthetic thinking skills.

For the formation of the students' methodological knowledge of the concept at the 2nd propaedeutic stage special tasks were developed, which include to the structure of meta-knowledge didactic concept's notion. At this stage students assimilated the pedagogical notions of clusters "education", "pedagogical activity", "pedagogical process" and also got an understanding about the semantic network as a cognitive structure.

The main stage covered the study of the module "Education in the whole pedagogical process". The direct object of mastering students was the semantic network of didactic concepts. The substantive basis for the rational organization of students' independent work was the system of tasks for the component-wise mastery of didactic concepts. Tasks were presented with a view to increasing the degree of independence of the student's cognitive activity in their implementation.

The management strategy of the studying and research activities of students in mastering a particular concept was formed according to the specifics of the concept being learned, the students' epistemological style, adequate models of prescriptions, appropriate types of independent students work, relevant computer application forms. We characterize each of these components.

The specifics of the didactic concept is the objective complexity of its content and the degree of its novelty.

The epistemological styles (Royce, 1974) are the ways of the student's cognitive relation to the concept, which are manifested in the peculiarities of the individual "didactic-semantic space"., There are diagnostic tools identified to identify it: the method of definition, the depiction of the semantic space of the concept, the formulation of problems, the method of associations, etc. The epistemological style (rationalistic, empirical or metaphorical) is a result of the diagnostics. Students of different epistemological styles have different cognitive preferences in research activities: "rationalists" are oriented towards research, "empirics" prefer searching, "metaphorists" suitable reproducing and reconstructive-variable.

The main model-prescription (Tsyrkun, 2000) is constructive. It reflects the productive character of the teacher and students interaction in mastering didactic concepts. The basic rules of this model go back to the content of the activity of component-wise concepts' design. The implementation of the constructive model was supplemented by auxiliary model prescriptions (receptive, relaxopedic, instrumental, cultural, interactive, research). Depending on the level of autonomy of the student in the process of cognitive activity, a specific model-prescription determined the adequate type of independent work of students: reproducing, reconstructive-variable, partially-search and research.

In the conditions of intensive informatization of society today the using of a computer is a means of rational organization of students' learning. There are 3 forms of computer application, which relevant to the rational organization of students' studying and research activities: quasi-teacher, tool, provider. Using a computer in the form of a quasi- teacher is effective when the computer program "implements" the functions of the teacher at a particular stage of learning faster or more qualitatively than the teacher himself can do. The use of a computer as a tool is associated with 
the following aspects: computer support for a lesson (presentation); the use of computer as a means of multimedia (demonstration of video clips of lessons, speeches of scientists, etc.). In the form of a provider a computer provides: computer support for students' activities that are not directly related to the learning process (searching for necessary information, access to distant resources of information, etc.); computer support for the activities of the teacher related to the preparation of the lesson and the necessary teaching materials (planning, developing individual tasks, finding the necessary information, etc.).

In the process of comprehension of didactic concepts students systematically mastered the activity of component-wise design of concepts. After that they could independently master concepts and incorporate them into the system of those already comprehended. At the final lesson each student defended own project of complementation of the didactic concepts system's semantic network.

We conducted a pedagogical experiment to assess the impact of our technology on the quality of didactic concepts students' comprehension. It was implemented on the base of the Belarusian higher education institutions: Belarusian State Pedagogical University named Maxim Tank, Brest State University and Gomel State University. All kinds of pedagogical experiment covered 363 students and 87 postgraduate students.

Quantitative assessment of the quality of didactic concepts students' comprehension by students was carried out using an integral indicator - a cumulative comprehension index. The positive impact of our technology on the quality of didactic concepts students' comprehension manifested itself in a higher value of the comprehension index of didactic concepts in the experimental group (E - 0.75) compared to the control $(\mathrm{K}-0.42)$, as well as in all components: mastering the metaknowledge didactic concept's ( $\mathrm{E}-0.81, \mathrm{~K}-0.45$ ), the component-wise comprehension completeness of the didactic concepts' content (E - 0.68, $\mathrm{K}-0.44)$, comprehension of the system of didactic concepts ( $\mathrm{E}-0.77, \mathrm{~K}-0.37$ ).

Fig. 3 shows the dynamics of the comprehension of didactic concepts in the consistency of their formation. The sequence of concepts was adopted emergently: the quality of comprehension of the previous concept determined the improvement of the quality of comprehension of the subsequent, and also caused the improvement of the quality of comprehension of previous concepts. This manifested the cumulative effect of our technique on the quality of didactic concepts students' comprehension.

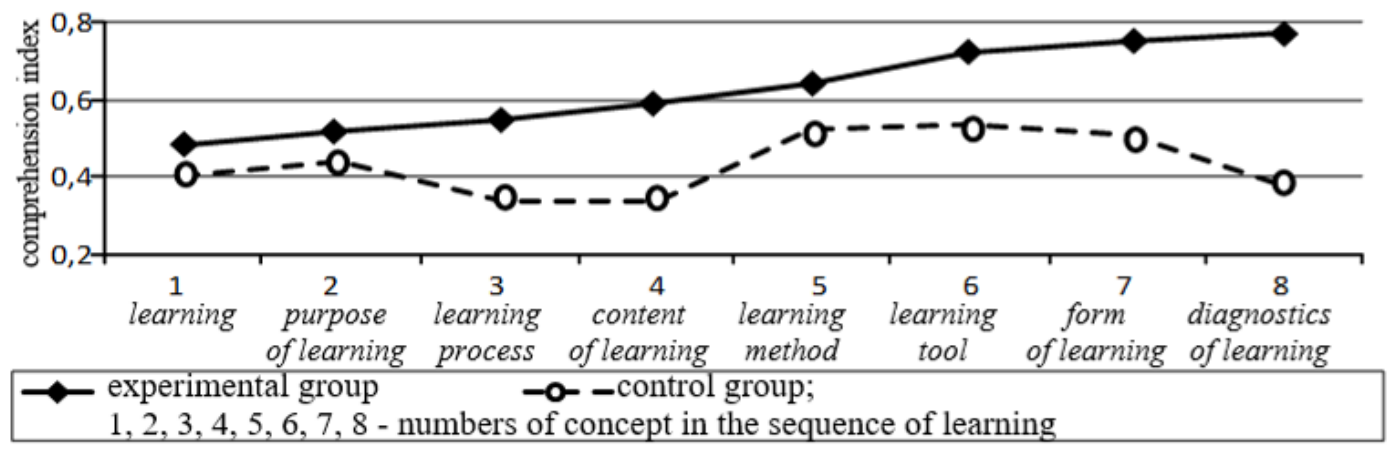

Fig. 3. The dynamics of didactic concepts comprehension in the control and experimental groups

According to the value of comprehension index each student were distributed for the levels of comprehension, which is shown in Fig. 4 from the lowest (descriptive) to the highest (generative). 


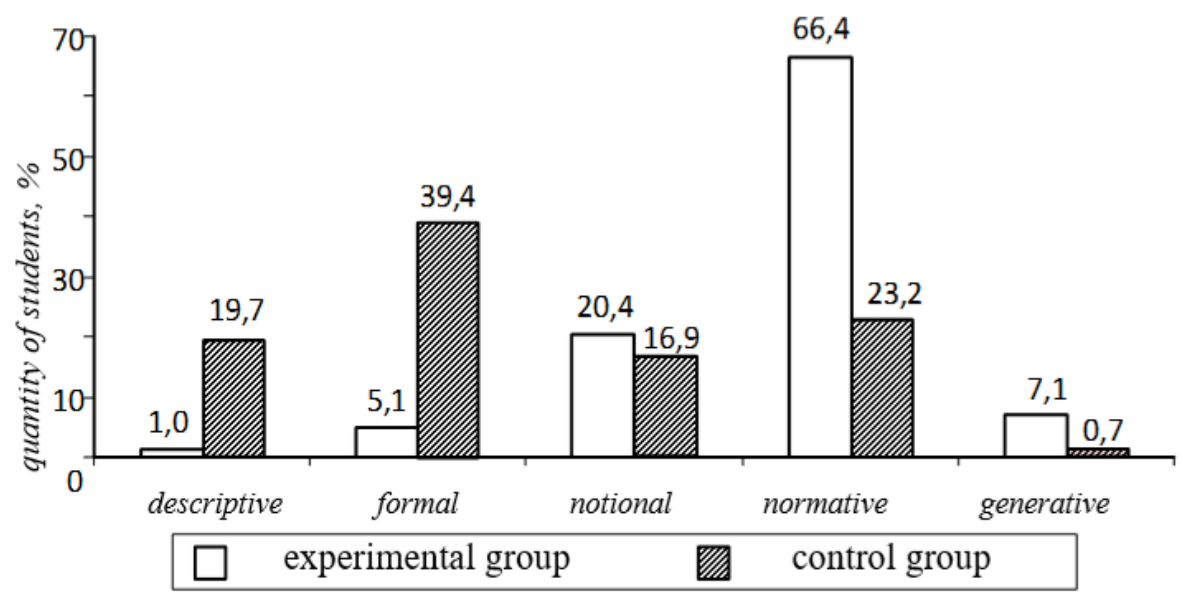

Fig. 4. Distribution of students of experimental and control groups according to the levels of comprehension of didactic concepts

In addition at the result of the experiment was revealed that author's technique of rational organizing students' studying and research activities provides a higher level of development of students' mental operations, as well as the formation of knowledge of a methodological kind. Statistical comparison of the quality of comprehension of didactic concepts in the control and experimental groups (criteria $\chi^{2}$ and correlation analysis) confirmed that this technique is more effective than the traditional one at the level of statistical significance $\alpha=0.05$.

\section{Conclusion}

As the result of a pedagogical experiment on the basis of quantitative and qualitative analysis the research hypothesis was confirmed. It is proved that the author's technology is author's technique of rational organizing students' studying and research activities on the basis of didactic concepts' design has a significant impact to the quality of students concepts' comprehension; the mastered of concepts design activity determines the intellectual self-development of the students.

The metacognition concept's notion of the formation of didactic concepts is an effective solution of the classical knowledge-transfer problem and allows to organize the process of knowledge formation in unity with the methods of their comprehension according the capability of person comprehension.

The pedagogical intellectics is the basis for creating a new constructive-activity approach to the process of the concept mastering and also opens new possibilities in the area of knowledge transfer.

\section{Acknowledgements}

The author is grateful for her scientific adviser (Full) Professor Ivan Tsyrkun for the opportunity to implement activities in the scientific school of modeling and organizing of innovation education. 


\section{References}

1. Vygotsky, L. S. Myshleniye i rech'. Problemy psikhologii razvitiya rebenka [Thinking and speaking. Problems of child development psychology] // Selected Psychological Studies. Moscow: APS RSFSR, 1956.

2. Tsyrkun, I. I., Punchyk, V. N. Pedagogicheskaya intellektika: didakticheskiy aspekt [Pedagogical intellectics: didactic aspect]: monograph. - Saarbrücken: LAP LAMBERT Academic Publishing GmbH \& Co. KG, 2011.

3. Chuprikova, N. I. Umstvennoye razvitiye i obucheniye (k obosnovaniyu sistemnostrukturnogo podkhoda) [Mental development and training (to substantiate the systemstructural approach)]. - Moscow: Publishing House Mosk. psycho-soc. inst.; Voronezh: MODEK, 2003.

4. Vekker, L. M. Psikhika i real'nost': yedinaya teoriya psikhicheskikh protsessov [Psikhika i real'nost': yedinaya teoriya psikhicheskikh protsessov]. - Moscow: Smysl, 1998.

5. Lobanov, A. P., Zhuravkina, I. S. Kognitivnaya psikhologiya [Cognitive psychology]. Minsk: BSPU, 2018.

6. Chervinskaya, K. R. Komp'yuternaya psikhodiagnostika [Computer psychodiagnostics]. - St. Petersburg: Speech, 2003.

7. Pospelov, D. A. Situatsionnoye upravleniye: teoriya i praktika [Situational management: theory and practice]. - Moscow: Science, 1986.

8. Bruner, J. Psikhologiya poznaniya: Za predelami neposredstvennoy informatsi [Psychology of knowledge: Beyond the immediate information] / ed. by A. R. Luria. - Moscow: Progress, 1977.

9. Royce, J. R. Cognition and knowledge: Psychological epistemology // J.R. Royce, E. Carterette, Moscow. Fridman (Eds.). Handbook of Perception. - N.Y .: Acad. Press, 1974. V. 1. - P. 149-176.

10. Tsyrkun, I. I. Sistema innovatsionnoy podgotovki spetsialistov gumanitarnoy sfery [The system of innovative training of specialists in the humanitarian sphere]. - Minsk:

Tekhnalogiya, 2000. 